\title{
The shear strength of pre-tensioned I beams with unreinforced webs*
}

\author{
by P. D. Arthur, B.Sc., A.M.I.C.E.
}

\author{
Contribution by R. G. Matheson, B.Sc., D.I.C. \\ Imperial College of Science and Technology
}

Mr Arthur's paper on the shear strength of concrete, particularly on pre-tensioned I beams, represents a valuable contribution to the problem of the diagonal cracking of prestressed members, and presents a very interesting summary and comparison of five previously published works on the topic of diagonal cracking and shear-strength prediction. It was informative to study Figures 10 and 11 and observe five independent expressions for cracking load compared with each other and with the current American and British criteria for shear-strength design. It is graphically apparent that Mr Arthur's rational choice of parameters and the resulting semi-empirical equation 8 are in good agreement with the other expressions derived from independent experimental data, and with established code requirements. The proposed equation 9 is therefore established as a valid, semi-rational expression for shear-strength design. However, like the early shear-strength equations developed from the work of researchers such as Clark, Hognestad, Evans, etc. and later by the authors quoted in Mr Arthur's paper, the proposed equation must be qualified by the range of variables covered in the test series, and so its application is limited. This limitation is carefully pointed out by $\mathrm{Mr}$ Arthur, but this restriction is inherent to any empirical approach and it has become apparent in the recent literature on shear-strength prediction that the empirical approach must be adopted. It would now seem that, when enough empirical data have been compiled, organized together, and generally accepted by the various investigators and committees on standards, the prediction of the diagonal cracking load for a specific range of design variables will be possible. Reaching this point would appear to be only a matter of time and resources, and from a comprehensive search of the present backlog of literature on the subject, it might be said that a very wide range of design formulae might now be set down.

If this approach to the problem is accepted, it would seem that the solution to the shear problem is close at

* Pages 199 to 210 of Magazine No. 53 hand, so a formula like equation 9 derived by $\mathrm{Mr}$ Arthur, and extended as he suggests in his sixth conclusion, will represent such an answer. However, I would like to suggest that formulae like equation 9 , derived for the diagonal cracking load, represent the solution to a simplified model of the shear-failure mechanism which produces a safe, conservative design criterion but an uneconomical and somewhat unimaginative presentation of the over-all shear-failure problem. I would like to question Mr Arthur's decision to restrict his formula, as other investigators have done, to the diagonal cracking load, while, at the same time, he indicates the reserve of strength that generally exists after the diagonal crack develops.

Many investigators have suggested that the strength reserve that exists after diagonal cracking must be considered in order to formulate the actual shearfailure mechanism, and I feel Mr Arthur should stress this point further. Design formulae should, of course, be the logical end-product of any research but the emphasis and object of the Magazine of Concrete Research would appear to be academic and so I suggest that the full shear-failure mechanism should be explained in order to stimulate further research in the post-cracking behaviour of beams under combined loading due to moment and shear forces. Like $\mathrm{Mr}$ Arthur, previous reporters have discussed the significance of diagonal cracking on the structural response of beams and also the fact that there is generally a strength reserve after the crack develops. However, there appears to be a lack of reports linking these two phenomena, and there are few proposals for shearstrength formulation which emphasize and include the strength reserve that has been reported after diagonal cracking.

In concrete members subjected to combined loading, the formation of diagonal (shear) cracks causes internal stress redistribution which may lead to member and structural failure at a load which is less than the member's flexural capacity. Many rational and semi-empirical proposals have been suggested over the past seventy years for the analysis of such failures and most authorities today favour a flexural theory modi- 
fied to include the effects of the shear force. The modern theories are based on a combination of the appropriate equilibrium and deformation conditions, and lead to the evaluation of a limiting (shear-reduced) ultimate moment. The equilibrium conditions are assumed to be the same as those associated with pure flexural failure and can be formulated from the sketches shown in Figure I. The equilibrium conditions are:

$$
\begin{gathered}
T=C \\
p f_{s} b d=f_{c} b d k_{u} \\
k_{u}=p f_{s} / f_{c} \\
M_{c} \Delta f_{c} k_{u} b d^{2}\left(1-k_{2} k_{u}\right) \\
\text { and } M_{t} \Delta f_{s} p b d^{2}\left(1-k_{2} k_{u}\right)
\end{gathered}
$$

where $T=$ internal tension force at failure

$C=$ internal compressive force at failure

$p=$ percentage of longitudinal reinforcement

$f_{s}=$ steel stress at failure

$f_{c}=$ average concrete stress in the compressive zone at failure

$b \quad=$ width of the top flange

$d=$ depth to the centroid of the steel

$M_{c}=$ internal compressive moment

$M_{t}=$ internal tensile moment

$k_{2}=$ depth ratio locating the internal compressive stress resultant

$k_{u}=$ depth ratio locating the neutral axis at failure.

The problem is not the formulation of the state of equilibrium for the mechanism; the problem lies in representing the deformations that occur in the shearfailure mechanism, (produced by a diagonal crack) in order to arrive at a compatibility relationship required to supplement the above-mentioned equilibrium conditions. Diagonal cracks distort the linear strain distribution currently used in flexural ultimate strength analysis and so some other deformation condition must be used. Mathematically this means that the conventional linear strain distribution must be modified to account for the effects of diagonal cracking; or, the concept of a kinematical model representing the shearfailure mechanism should be further investigated. These two approaches to the formulation of a compatibility relation are illustrated in Figures II and III, and were first introduced in 1957 by Zwoyer and Walther respectively.

Recently an experimental programme has been initiated at Imperial College to investigate the strength reserve in prestressed beams after diagonal cracking. The tests have been designed to study the formation and propagation of cracks to the shear zone, and the structural response to combined loading during and after the formation of diagonal cracks. The main objective of the tests is to observe the deformations
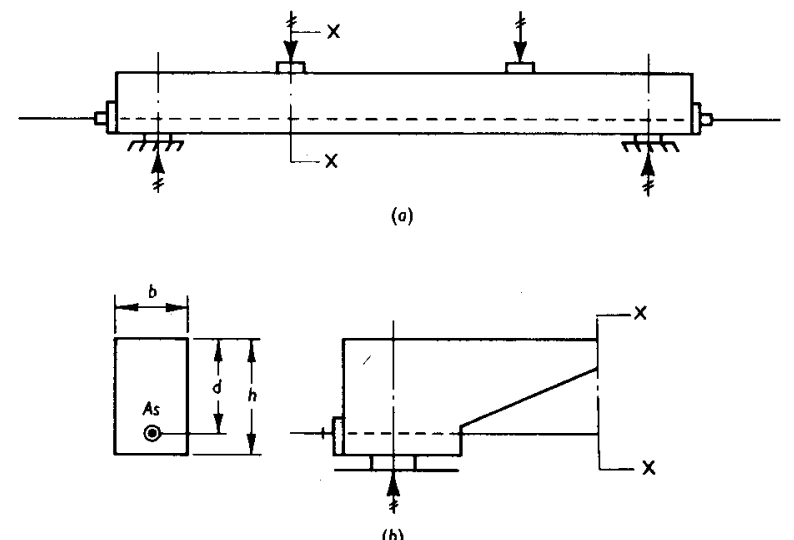

(b)

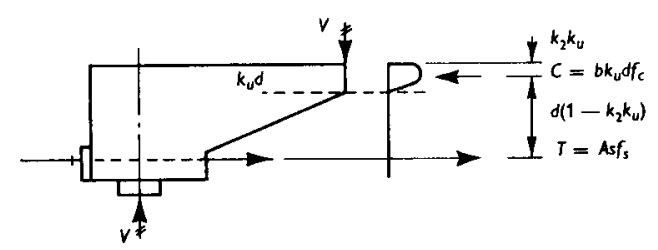

(c)

Figure I: Equilibrium conditions for a beam failing under combined loading due to moment and shear. (a) Profile of a beam subjected to combined loading. (b) Idealized shear-failure mechanism resulting from diagondl cracking. (c) Stress-resultant distribution in equilibrium with external loads.

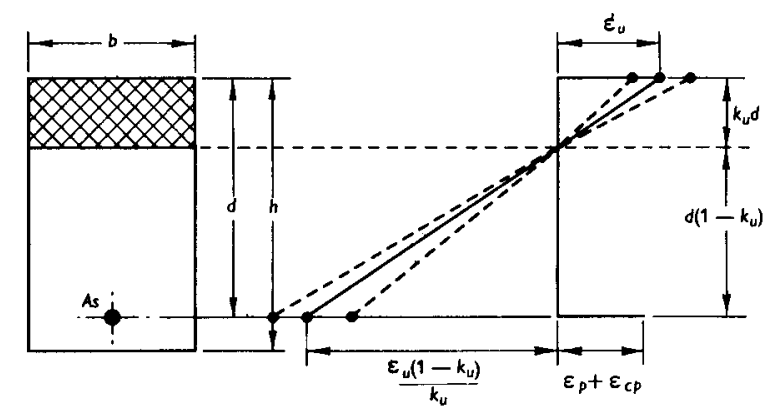

Figure II: Bending compatibility condition modified for shear failure.

For bending: $\varepsilon_{s u}=F_{\mathrm{B}}\left(\frac{\varepsilon_{u}\left(1-k_{u}\right)}{k_{u}}\right)+\varepsilon_{p}+\varepsilon_{c p}$

For combined loading: $\varepsilon_{s u}=F \mathrm{~s}\left(\frac{\varepsilon_{u}\left(1-k_{u}\right)}{k_{u}}\right)+\dot{\varepsilon}_{p}+\varepsilon_{c p}$.

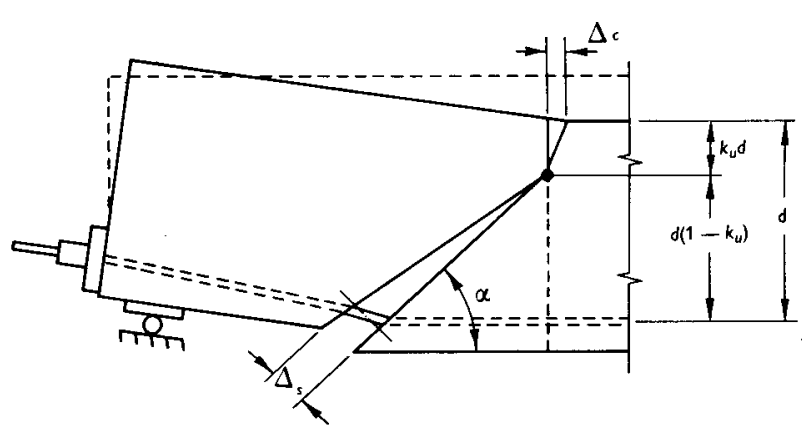

Figure III: Rotational deformation condition,

$\Delta_{c} / \Delta_{s}=k_{u} \sin \alpha /\left(1-k_{u}\right)$, proposed by Walther for a beam failing under combined loading. 
that occur after diagonal cracking, and to relate these deformations to the strength reserve after cracking. Many investigators have shown that stress redistribution occurs because of inclined cracking and have suggested mathematical models to formulate a shearcompatibility condition, but there is a definite lack of information on the actual kinematics of the shear-

\section{Reply by the author}

Mr Matheson's comments on the paper are appreciated and his emphasis on the fact that the reserve of strength above the diagonal cracking load requires more study is sound. Further experimental work to confirm and develop the ideas put forward by Walther and other authors will probably be the most fruitful approach. The Russian design approach to the problem of shear in reinforced concrete is along similar lines. ${ }^{(5)}$

However, it is clear from Figure 7 that, even if a moment-shear solution were found, the scatter of the points is so wide that, for beams similar to those tested, it could not be relied upon for design purposes. The scatter might be considerably reduced if web reinforcement were provided but a study of web reinforcement was outside the scope of the original series of tests.

The results of the test programme now under way at Imperial College will be awaited with interest. failure mechanism. This research is designed to observe the mechanism from its formation due to inclined cracking, until the member fails in shear.

I commend $\mathrm{Mr}$ Arthur for his extensive report on the problem of diagonal cracking and shear-strength design, and I look forward to his comments on the work outlined above.

\section{REFERENCES}

1. WALTHER, R. The shear strength of prestressed concrete beams. Third Congress of the Fédération Internationale de la Précontrainte, Berlin, 1958. London, Cement and Concrete Association, 1959. Papers volume. pp. 80-100. Session I, Paper 9.

2. SOZEN, M. A., ZWOYER, E. M. and SIESS, C. P. Strength in shear of beams without web reinforcement. Urbana, University of Illinois April 1959. pp. 69. Engineering Experiment Station Bulletin No. 452.

3. EVANS, R. H. and hOSNY, A. H. H. The shear strength of posttensioned prestressed concrete beams. Third Congress of the Fédération Internationale de la Précontrainte, Berlin 1958. London, Cement and Concrete Association, 1959. Papers volume. pp. 112-132. Session I, Paper 11.

4. CLARK, A. P. Diagonal tension in reinforced concrete beams. Journal of the American Concrete Institute. Proceedings Vol. 48, No. 10. October 1951. pp. 145-156.

5. SIGALOV, E. and Strongin, s. Reinforced concrete. Moscow, Foreign Languages Publishing House, 1962. pp. 393. 